\title{
Investigating 3,3-Diaryloxetanes as Potential Bioisosteres in Drug Discovery
}

\author{
Maryne A. J. Dubois, ${ }^{a}$ Rosemary A. Croft,${ }^{a}$ Yujie Ding, ${ }^{a}$ Chulho Choi, ${ }^{b}$ Dafydd R. Owen, ${ }^{c}$ \\ James A. Bull, ${ }^{*, a}$ and James J. Mousseau*,b \\ ${ }^{a}$ Department of Chemistry, Imperial College London, Molecular Sciences Research Hub, White City Campus, Wood Lane, \\ London W12 0BZ, UK. \\ ${ }^{b}$ Medicine Design, Pfizer Worldwide Research, Development and Medical, 445 Eastern Point Rd., Groton, CT 06340, USA. \\ ${ }^{c}$ Pfizer Medicine Design 610 Main St, Cambridge, MA 02139, USA
}

KEYWORDS Bioisoteres, oxetanes, MMPA.

\begin{abstract}
Oxetanes have received increasing interest in medicinal chemistry as attractive polar and low molecular weight motifs. The application of oxetanes as replacements for methylene, methyl, gem-dimethyl and carbonyl groups has been demonstrated to often improve chemical properties of target molecules for drug discovery purposes. The investigation of the properties of 3,3-diaryloxetanes, particularly of interest as a benzophenone replacement, remains largely unexplored. With recent synthetic advances in accessing this motif we studied the effects of 3,3-diaryloxetanes on the physicochemical properties of 'drug-like' molecules. Here, we describe our efforts in the design and synthesis of a range of drug-like compounds for matched molecular pair analysis to investigate the viability of the 3,3-diaryloxetane motif as a replacement group in drug discovery. We conclude that the properties of the diaryloxetanes and ketones are similar, and generally superior to related alkyl linkers, and that diaryloxetanes provide a potentially useful new design element.
\end{abstract}

The application of bioisosteres to replace problematic functionality is a common strategy in medicinal chemistry. In doing so, the goal is often to maintain target activity and binding kinetics, while simultaneously improving aspects of physicochemical properties and/or improving toxicological profiles. ${ }^{1}$ Synthetic efforts continue to focus on providing new or improved access to novel isosteres, ${ }^{2}$ as part of ongoing attempts to reduce synthesis as a significant rate-limiting step in drug discovery. ${ }^{3}$ The subsequent understanding of the properties of new motifs as well as their effects in a drug discovery setting allows chemical synthesis to have a significant influence in driving novel analogue design. Notable examples include the adoption of sulfoximines ${ }^{4}$ and bicyclo[1.1.1]pentane motifs, ${ }^{2 a}$ as well as oxetanes, ${ }^{5,6}$ each offering attractive physicochemical properties and increased 3-D character.

Studies on oxetanes in medicinal chemistry came to prominence with Carriera's work illustrating the potential of 3,3-disubstituted oxetanes as a replacement group for gem-dimethyl motifs, and as isosteres for cyclic ketones and morpholines, in spirocyclic examples (Figure 1). ${ }^{6}$ The incorporation of this polar and low molecular weight moiety has been demonstrated to afford compounds with enhanced properties: improved metabolic stability, solubility and lipophilicity is often observed, while also increasing the $\mathrm{sp}^{3}$-content $\left(\mathrm{Fsp}^{3}\right)$ of a target compound. ${ }^{5-7}$ The ring structure gives the endocyclic oxygen atom increased Lewis basicity and accessibility of the lone pairs, providing hydrogen bond accepting capability comparable to that of ketones. ${ }^{8}$ Other recent reports include a peptidomimetic application whereby the carbonyl of an amide group is replaced by

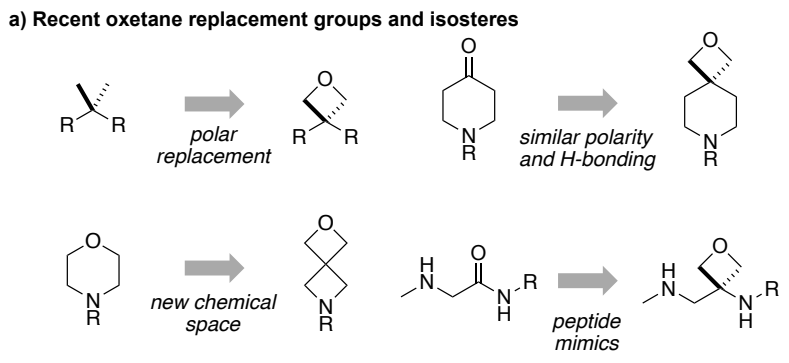

b) This work: Diaryloxetanes as bioisosteres. A matched-molecular pairs study

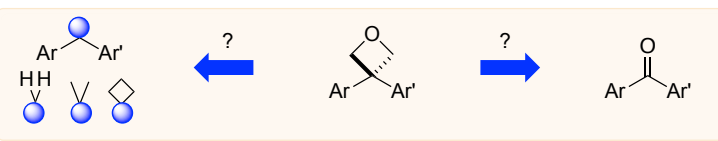

Figure 1. Developments of oxetane bioisosteres

3 -aminooxetanes, ${ }^{9}$ as well as oxetan-3-ol as an alternative isosteric replacement of carboxylic acid. ${ }^{10,11}$

3-Mono- and 2-substituted-oxetanes have also seen significant synthetic and medicinal investigation, and are increasingly investigated in SAR studies, and are present in bioactive compounds. ${ }^{5,12,13}$ However, it is 3,3-disubstituted derivatives that have seen the most attention, as they benefit from not introducing a stereocenter, and increase steric protection to avoid ring opening pathways.

We became interested in 3,3-diaryloxetanes as potential bioisosteres for benzophenones that may offer improved properties (Figure 1b). While benzophenones have been applied to ligate probes in chemical biology applications, ${ }^{14}$ this innate 
reactivity often makes this highly activated ketone undesirable in medicinal chemistry programs. They often act as photosensitizers, exhibiting phototoxicity through nucleobase modifications. ${ }^{15}$ At Pfizer, as a strategy to mitigate this phenomenon, several internal programs also described a need for 3,3-diaryloxetanes for key analogs. However, mining of internal data demonstrated that accessing this architectural structure was often challenging to access, and as a result attempts towards these design targets were often halted. This was corroborated in with a survey of the literature, where as of early 2015, there were few viable synthetic methods reported towards 3,3-diaryloxetanes. Most relied on the low yielding ring closure of 1,3 -diols, ${ }^{16}$ or a Paternò-Büchi cycloaddition, which gave undesired 2,2,3,3tetrasubstituted oxetanes. ${ }^{17}$ Given the knowledge of our internal and external data, we initiated an industrial-academic collaboration between Pfizer and Bull (Imperial College London) to discover new methods to form these aliphatic heterocycles. This partnership expediently developed a new way into 3,3-diaryloxetanes through a lithium-catalyzed Friedel-Crafts manifold, which provided unprecedented access to decorated 3,3-diaryloxetane motifs. ${ }^{18}$ Mechanistic understanding enabled the development of other interesting 3,3-disubstituted oxetanes. ${ }^{11,19}$ Furthermore, we have been able to demonstrate that 3,3-diaryloxetanes are robust to a range of chemical transformations, enabling access to a range of compounds with diverse functionality.

With these new methods in hand, and cognizant of the lack of understanding of the impact of 3,3-diaryloxetanes on physicochemical properties, we proceeded to a matched molecular pair analysis (MMPA) to probe the effect of replacing a benzophenone with a diaryloxetane on lipophilicity, cell permeability, clearance, solubility, and chemical stability, amongst others. In addition we rationalized that the oxetane could be an effective isostere for metabolically labile diarylmethane groups, as well as lipophilic gem-dimethyl, and cyclobutane derivatives. Herein we disclose our efforts in the preparation of these drug-like compounds as well as the analysis of the subsequent MMPA of physicochemical and biological properties of oxetane, ketone, and other linkers.

Initially, a series of $>150$ lead-like and drug-like compounds was designed with properties often desirable in a pharmaceutical setting. ${ }^{20}$ From a virtual screen, 16 compounds were selected for synthesis, with a range of lipophilic values $(c \log D$ 0.5-5.0) as well as 8 phenolic precursors to provide a handle for divergent synthesis. Two series were established: 1) the indole series including five linkers (a-e), and 2) the $p$-methoxyphenyl series that constituted oxetane-ketone (a,b) pairs (Figure 2$)$. This provided a comparison of compounds differing by a single structural modification either by the linker in the central carbon or by the R group.
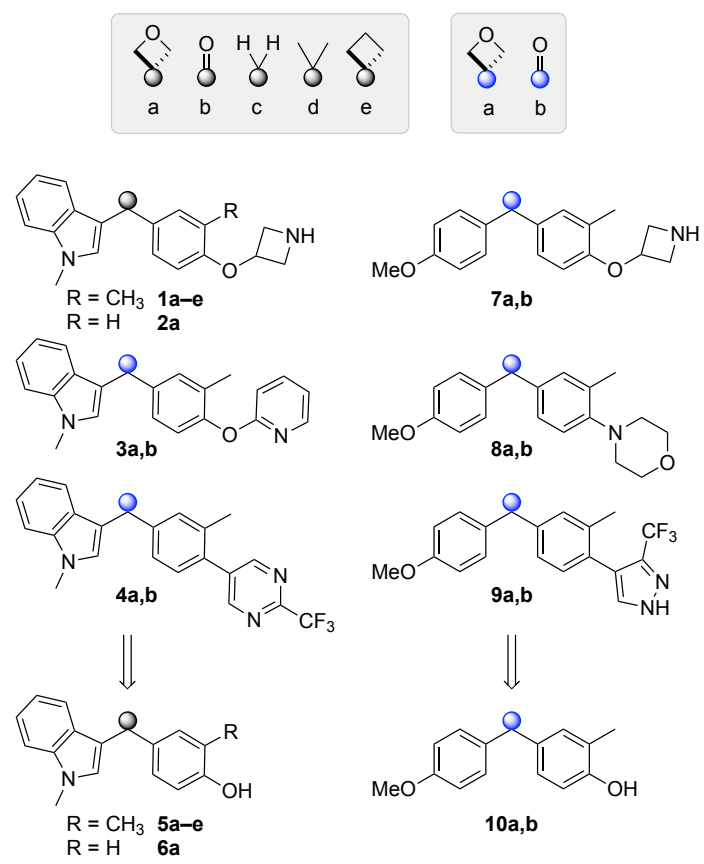

Figure 2. Selected molecules for the proposed pairwise analysis

The synthesis of targets 1a and 2a (scheme 1a) was achieved via a catalytic Friedel-Crafts alkylation from a readily accessible alcohol precursor, a method developed in our previously disclosed work. ${ }^{18}$ 3-Indolyloxetanol 11a was furnished from commercially available oxetanone and 3-iodo-methylindole in the presence of $n \mathrm{BuLi}$. Subjecting oxetanol 11a to a FriedelCrafts alkylation using $o$-cresol or phenol and an inexpensive lithium triflimide catalyst under mild conditions led to diaryloxetane $5 \mathbf{a}$ in $67 \%$ yield, whereas oxetane $\mathbf{6 a}$ was obtained in $28 \%$. This lower yield was due to the formation of oxetanoether and dihydrobenzofuran side products consistent with previous work. $^{18,19 \mathrm{a}}$

Treatment of arylbromide 14 with $n \mathrm{BuLi}$ and methylindol-3carboxaldehyde resulted in an unstable alcohol, which after oxidation and deprotection steps gave desired ketone $\mathbf{5 b}$ in $61 \%$ yield over 3 steps (scheme 1a). The synthesis of compounds $\mathbf{5 c}-$ 5e was initially attempted using 3-indolylmethanols analogous to oxetanol 11a. However, in contrast to methylindolyl-oxetanol 11a, 3-indolylmethanols 11c and 11e (not shown) were unstable under acidic conditions when subjected to the FriedelCrafts reaction. Dimerization, trimerization, and decomposition of the indolylmethanol precursors were observed (see supporting information). ${ }^{21}$ Alternatively, Friedel-Crafts alkylation of accessible alcohols $\mathbf{1 5 c}, \mathbf{d}$ and $\mathbf{1 6 e}$ provided access to derivatives $\mathbf{5 c}-\mathbf{5 e}$ (scheme 1a). Both methylene 5c and gem-dimethyl $\mathbf{5 d}$ derivatives were synthesized in good to excellent yields, and cyclobutane 5e was obtained in $92 \%$ yield after removal of the TIPS protecting group. Interestingly, the calcium triflimide catalyst was found to be more efficient for the synthesis of compounds $\mathbf{5 c}, \mathbf{5 d}$ and $\mathbf{1 7 e}$ relative to the lithium triflimide catalyst which was optimized for the oxetane system. ${ }^{22}$ 

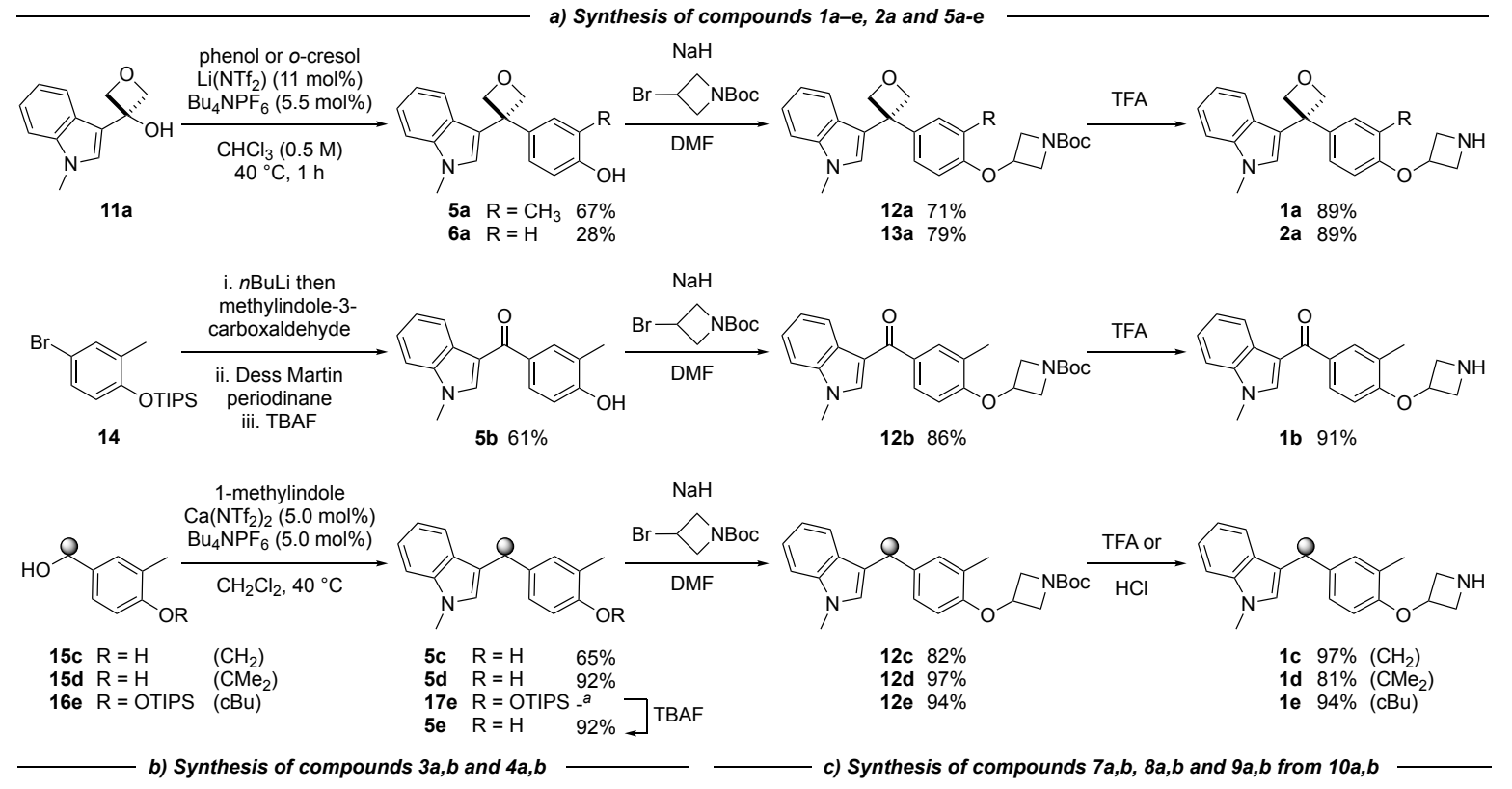
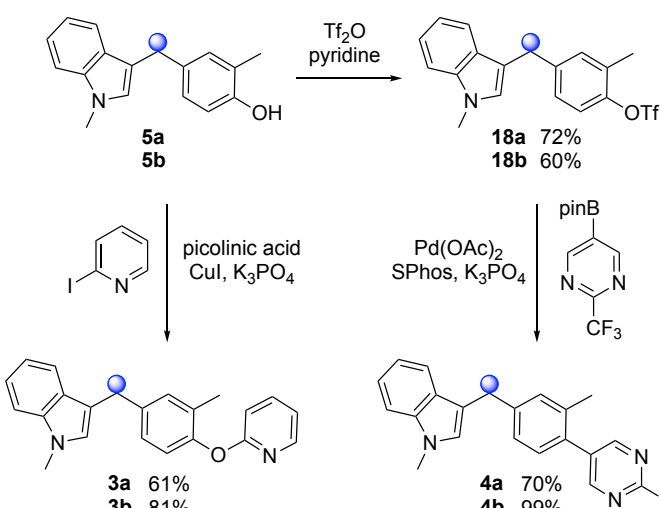

3b $81 \%$

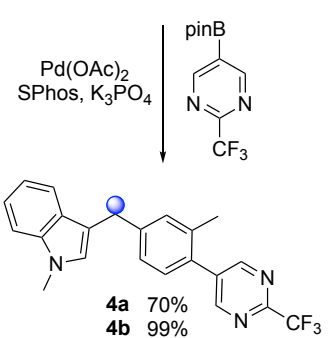

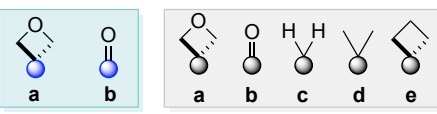

${ }^{a}$ not isolated. Yield of $\mathbf{5 e}$ corresponds to yield over 2 steps.
Alkylation of phenols 5a-5e and 6a with an $N$-Boc protected azetidine gave ethers 12a-12e and 13a in excellent yield from $71 \%$ to $97 \%$ (scheme 1a). Of note, the use of trifluoroacetic acid (TFA) to deprotect the azetidine amines did not lead to ring opening or decomposition of the oxetane ring, delivering both products 1a and 2a in excellent yield, and providing further support to the robustness and chemical stability of the 3,3-diaryloxetane motif. Notably, this was in contrast to the gem-dimethyl (1d) and cyclobutane (1e) analogues, which were found to be unstable under these conditions. Instead, 1d and 1e were obtained using $\mathrm{HCl}$ in $81 \%$ and $94 \%$ yield respectively. The ketone (1b) and methylene (1c) derivatives were smoothly obtained using TFA. Compounds 1a-1e were made in $20-81 \%$ yield in three to five steps from the corresponding alcohol or bromoarene.

Copper-catalyzed Ullman couplings proceeded with both phenols $\mathbf{5 a}$ and $\mathbf{5 b}$ yielding oxetane $\mathbf{3 a}$ and ketone $\mathbf{3 b}$ in $61 \%$ and $81 \%$ yield respectively (scheme $1 \mathrm{~b}$ ). The phenols were readily converted to the triflates under standard triflation conditions. Subjecting triflates $\mathbf{1 8 a}$ and $\mathbf{1 8 b}$ to Suzuki-Miyaura cross- coupling with a pyrimidine pinacol boronic ester gave both arylated products $\mathbf{4 a}$ and $\mathbf{4 b}$ in $70 \%$ and $99 \%$ yield.

Diaryloxetane 10a was formed using similar conditions as described for 5a, whereas ketone $\mathbf{1 0 b}$ was synthesized via the treatment of a Weinreb amide with an aryllithium (see Supporting Information). Then, the addition of the $\mathrm{N}$-Boc-protected azetidine and subsequent Boc-deprotection was achieved successfully yielding both amines $\mathbf{7 a} / \mathbf{7 b}$ in $96 \%$ yield (scheme 1c). From triflates 20a and 20b, Buchwald-Hartwig amination gave morpholine substituted oxetane $\mathbf{8 a}$ and ketone $\mathbf{8 b}$ in 74 and $87 \%$ yield respectively. Suzuki-Miyaura cross-coupling afforded biaryl $9 \mathrm{a}$ and $9 \mathrm{~b}$ in $28 \%$ and $47 \%$ yield.

With the targets in hand we proceeded with our analysis. Given the common question that arises on the chemical stability of oxetanes, which could preclude application of these motifs in medicinal chemistry programs, we subjected the pairs to a $\mathrm{pH}$ stability assay. Figure 3 displays selected pairs of ketone/oxetane, as well as the alkyl linkers. 


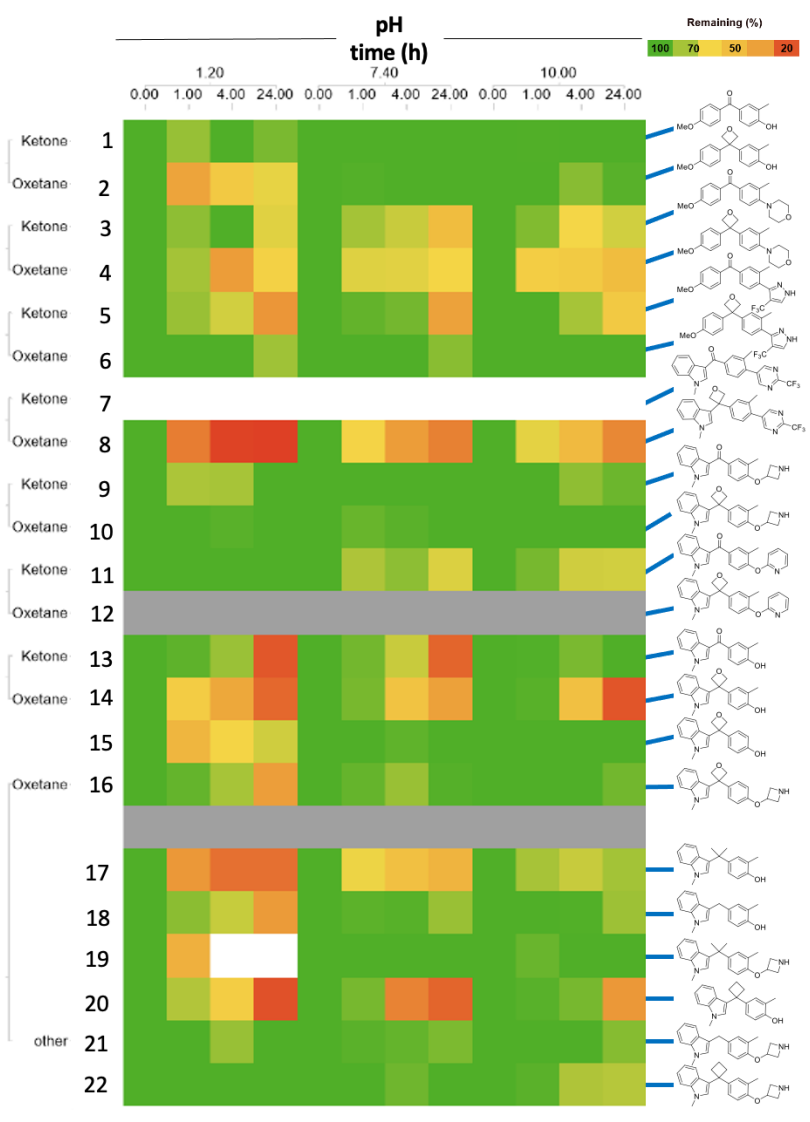

Figure 3. pH Stability of selected compounds

We were pleased to observe that the 3,3-diaryloxetanes were generally stable in acidic to basic conditions. Most substrates were tolerated at low $\mathrm{pH}$, even after $4 \mathrm{~h}$. The stability of the ketones was similar to the oxetanes. While the indole phenol oxetane and ketone $\mathbf{5 a}$ and $\mathbf{5 b}$ did demonstrate poorer stability at low $\mathrm{pH}$ (rows 13,14), this was on par with the corresponding gem-dimethyl (row 17), methylene (row 18) and cyclobutyl (row 20) derivatives, suggesting that the cause of the instability is the designed chemotype and not the linking functional group. Interestingly, removal of the $o$-methyl group on the phenol improved the stability (row 15).

The measured lipophilicity of the oxetane compounds $(e \log \mathrm{D})$ was across a range from 1.7-5.1, with an average of 3.4 over 9 compounds, and similar to the calculated values (see Supporting information for full details, as well as $s f \operatorname{LogD}$ data). It was clearly notable that the oxetane led to a significant decrease in measured $e \log \mathrm{D}(0.81$ units in elogD on average) in comparison to each of the methylene, gem-dimethyl, or cyclobutyl analogues, attributable to the polarity of the oxetane. Of particular interest was the effect relative to the corresponding ketone, and we compared 5 matched pairs. Previous work with other 3,3disubstituted oxetanes suggested an increase in lipophilicity of 0.1 to $0.7 \log \mathrm{D}$ units. ${ }^{6 \mathrm{~b}}$ Interestingly, the indole series indicated an average increase of $0.58 \log$ units moving from the ketone to the oxetane (Figure 4). However, the $p$-methoxyphenyl series exhibited the opposite trend, whereby the lipophilicity was decreased of $0.30 \log$ units upon incorporation of the oxetane. Although the data disclosed herein suggests that the phenomenon will be series dependent, the combined values infer a similar trend to that reported by Carreira and others with an expected slight $\log \mathrm{D}$ increase for the oxetane in comparison to the ketone (0.24 eLogD units).

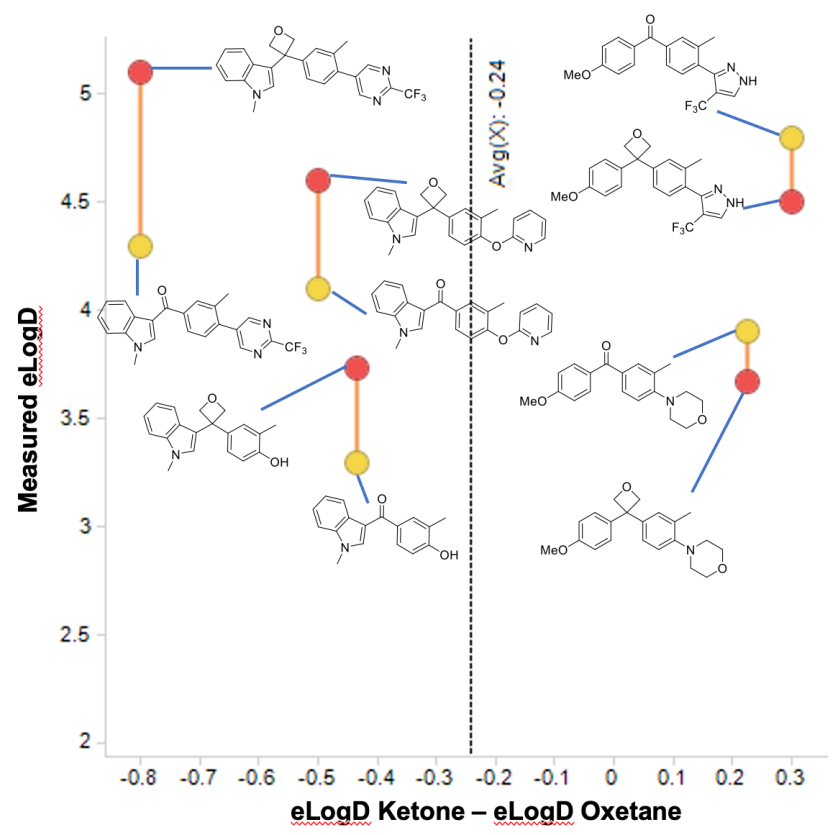

Figure 4. $\operatorname{LogD}$ shift of selected compounds

Clearance by human liver microsomes was low across the selection of compounds. In fact, with the five pairs for which data could be obtained, clearance by human liver microsomes were unchanged between compounds bearing the carbonyl and oxetane groups (Table 1).

Table 1. HLM of oxetanes vs ketones

\begin{tabular}{|l|c|c|c|c|}
\hline Oxetane & $\begin{array}{c}\text { HLM Clint } \\
\text { (uL/min/mg) }\end{array}$ & $\begin{array}{c}\text { HLM Clint } \\
\text { (uL/min/mg) }\end{array}$ \\
\hline
\end{tabular}

Cognizant that the clearance could be driven by $\log \mathrm{D}$, and given the similarity of those values between the pairs, a lipophilic metabolism efficiency (LipMetE) analysis was performed. LipMetE is an approach that was put forth in 2013 to describe the efficiency of a compound's metabolic stability relative to its lipophilicity. ${ }^{12 b}$ Seventeen compounds where metabolism and $\log \mathrm{D}$ values could be obtained were plotted (Figure 5). 


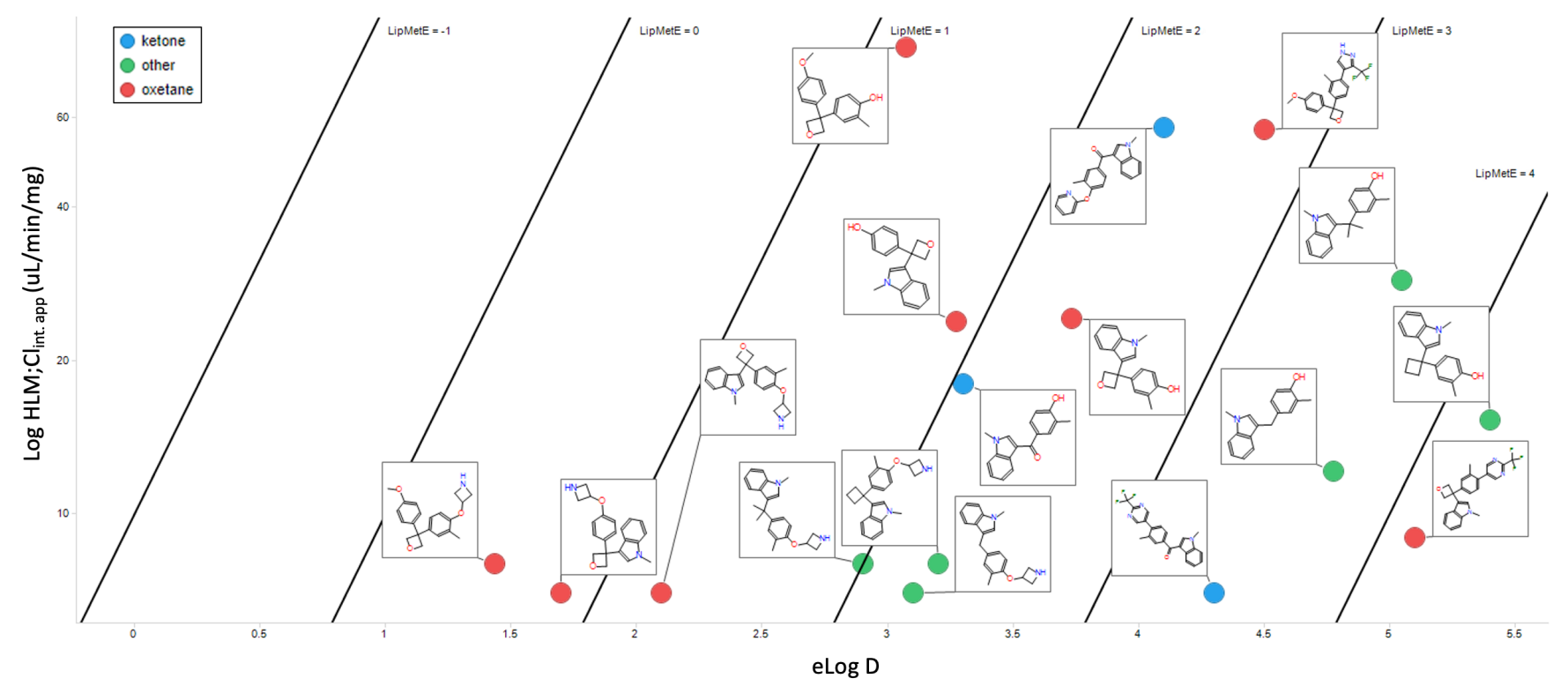

Figure 5. Lipophilic metabolism efficiency (LipMetE) analysis

Of the few values obtained with ketones, the LipMetE profile was slightly decreased relative to the oxetane. This could have been expected given the similarity in clearance, and in certain cases, lower $\log \mathrm{D}$ of the ketones. The observation of note was the comparison of oxetanes relative to other linker groups. The majority of the compounds exhibited a LipMetE of $>1$, suggesting that clearance as a function of $\log \mathrm{D}$ was favorable for most linkers. The two compounds with values $<1$, while oxetanes, demonstrated low clearance values with acceptable $\log \mathrm{D}$ values. The absolute clearance values for some of the non-oxygenated linkers is modest relative to their corresponding $\log \mathrm{D}$. This potentially surprising observation is valuable for medicinal chemists as it suggests the possibility of the introduction of 'friendly grease'. It is important to note that there does not appear to be a metabolic liability associated with the 3,3-diaryloxetane motif, and there is an improvement in LipMetE moving from the ketone to the oxetane.

The permeability of the 3,3-diaryloxetanes was universally improved relative to the corresponding methylene, gem-dimethyl and cyclobutyl variants (Figure 6). For example, both the methylene and cyclobutyl indole-cresol derivatives (5c and 5e) were determined to exhibited very poor cell permeability with an RRCK of $0.1 \times 10^{-6} \mathrm{~cm} / \mathrm{s}$. When replacing the linker with an oxetane the permeability improved to a very respectable $15.6 \times 10^{-}$ ${ }^{6} \mathrm{~cm} / \mathrm{s}$. The conformational constraints between the cyclobutyl and oxetanyl variants would be expected to be similar, and hence the improvement is due to the additional oxygen atom. The ketones were overall found to behave similarly to the oxetanes in cell permeability, with no clear trend when comparing the ketone and oxetanes. In three pairs permeability decreased moving form ketone to oxetane, one pair was unchanged, and two pairs demonstrated improved permeability with the oxetane. This data suggests that the inclusion of an 3,3-diaryloxetane can be a tactic to improve cell permeability relative to all carbon pairs, but does not necessarily equate to an improvement relative to the corresponding benzophenone.

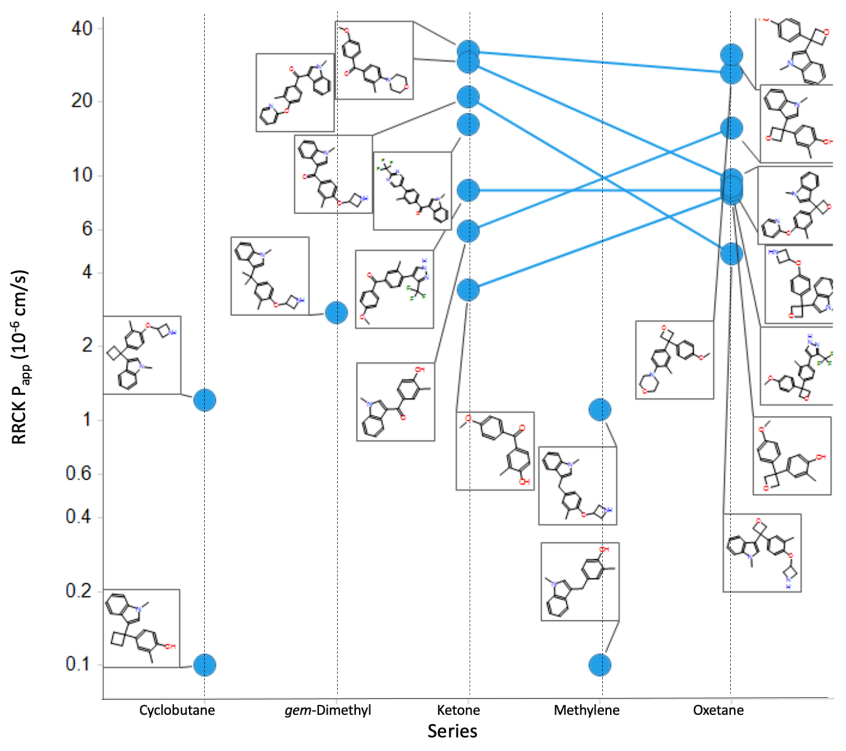

Figure 6. Comparison of cell permeability.

As our last parameter we considered the kinetic solubility of the prepared compounds. The solubility varied significantly based on peripheral structure. Comparison of the obtained results with the 3,3-diaryloxetanes and the corresponding ketones indicates that the solubility was largely unchanged by the inclusion of the oxetane. While some oxetanes did display improved profiles relative to the their isosteric counterparts (Figure 7 , rows $1 / 2$, $9 / 10,16)$, the solubility of the molecules appear to be governed primarily by the aryl components, and as such in these architectures, oxetanes cannot be guaranteed to improve a low solubility profile. 


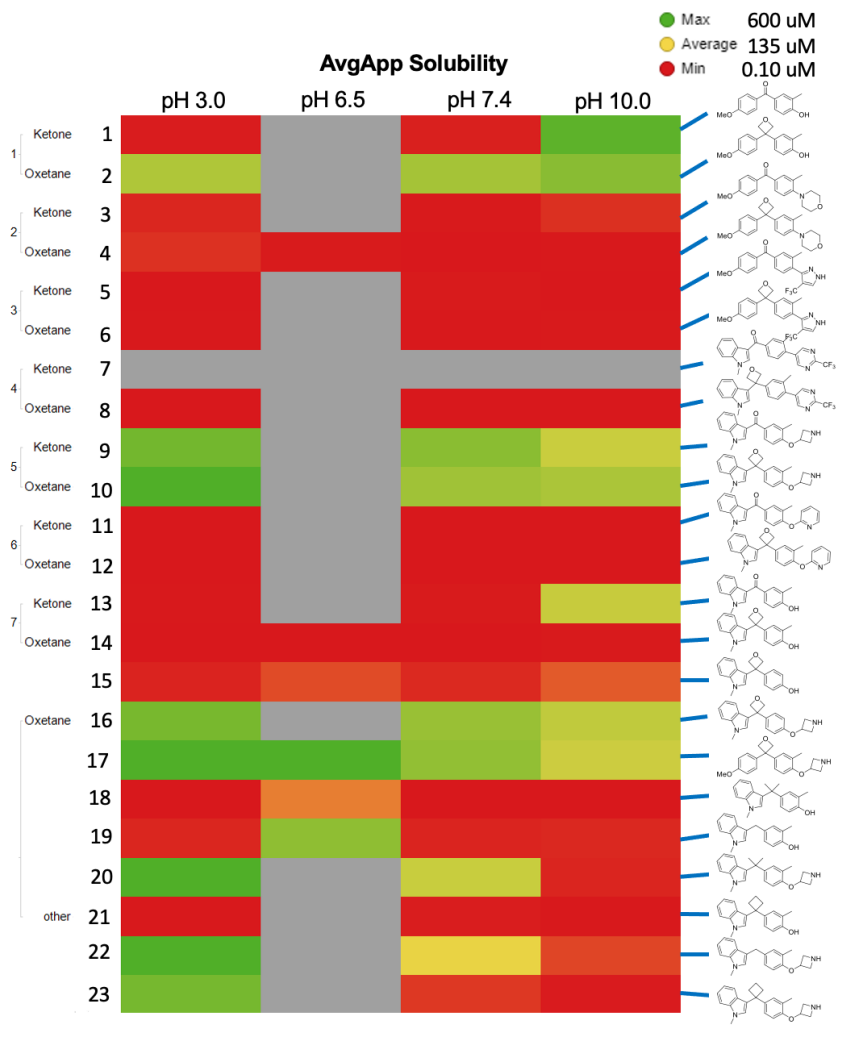

Figure 7. Comparison of solubility.

In summary, we have conducted the first study of the property space of 3,3-diaryloxetanes and related compounds in drug-like space, with direct comparisons to ketone and alkyl variants (methylene, gem-dimethyl, and cyclobutyl derivatives). We observed that the oxetane compounds are chemically stable to a range of $\mathrm{pH}$ and are no more prone to decomposition than other linker motifs. Indeed the oxetane examples showed advantageous stability within the synthetic sequences. The change in lipophilicity profile between oxetane and ketone was not uniform, as certain motifs displayed an increase in $\log \mathrm{D}$ while others were lowered. The $\log \mathrm{D}$ of the oxetane derivatives was significantly improved in comparison to the carbon-linkers. There was little change in metabolic stability when switching from a ketone to an oxetane, however improved profiles were observed relative to other isosteric equivalents. Cell permeability is markedly improved by changing a methylene, gem-dimethyl or cyclobutane to an oxetane or ketone, however, as with the $\log \mathrm{D}$, improvements from ketone to oxetane vary on a case by case basis. Lastly, the inclusion of an oxetane did not reliably improve solubility in these examined series.

Overall, the 3,3-diaryloxetanes displayed similar physicochemical properties to diaryl ketones, without the electrophilic and potential photochemical liabilities, and overall improved properties compared to methylene, gem-dimethyl and cyclobutane analogues. We have also further demonstrated the potential of the catalytic Friedel-Crafts methodology from 3-aryloxetan-3ols to form 3,3-diaryloxetanes in compounds with drug-like and lead-like properties. We conclude that the diaryloxetane motif may provide a valuable replacement for diarylketones, as well as for other diarylmethane motifs. Furthermore, we propose that the diarylmethane unit itself presents an attractive motif in underexplored chemical space that may find broader application in drug discovery as a new analogue design option without intrinsic liabilities.

\section{AUTHOR INFORMATION}

\author{
Corresponding Author \\ * james.mousseau@gmail.com \\ *j.bull@imperial.ac.uk
}

\section{ACKNOWLEDGMENT}

We gratefully acknowledge The Royal Society [University Research Fellowship, UF140161 (to J.A.B.), URF appointed grant RG150444 and URF enhancement grant RGF\EA 180031$]$, EPSRC [CAF to J.A.B. (EP/J001538/1)], Pfizer for studentship funding (M.D) and Imperial College London for a Presidents Scholarship (R.A.C). Dr. B. Gerstenberger and Dr. J. Montgomery are thanked for their contributions and assistance with visualizations. Dr. M. Perry and Dr. S. Wright are thanked for their input. Dr. Y. Fobian, Dr. D. Hepworth, Dr. D. Blakemore, and Dr. M. Bunnage are thanked for their support.

\section{REFERENCES}

(1) Meanwell, N. A. Synopsis of some recent tactical application of bioisosteres in drug design. J. Med. Chem. 2011, 54, 2529-2591.

(2) For selected examples, (a) Stepan, A. F.; Subramanyam, C.; Efremov, I. V; Dutra, J. K.; O'Sullivan, T. J.; DiRico, K. J.; McDonald, W. S.; Won, A.; Dorff, P. H.; Nolan, C. E.; Becker, S. L.; Pustilnik, L. R.; Riddell, D. R.; Kauffman, G. W.; Kormos, B. L.; Zhang, L.; Lu, Y.; Capetta, S. H.; Green, M. E.; Karki, K.; Sibley, E.; Atchison, K. P.; Hallgren, A. J.; Oborski, C. E.; Robshaw, A. E.; Sneed, B.; O’Donnell, C. J. Application of the Bicyclo[1.1.1]pentane Motif as a Nonclassical Phenyl Ring Bioisostere in the Design of a Potent and Orally Active $\gamma$ Secretase Inhibitor. J. Med. Chem. 2012, 55, 3414-3424. (b) Mykhailiuk, P. K. Saturated bioisosteres of benzene: where to go next ?. Org. Biomol. Chem. 2019, 17, 2839-2849.

(3) Campos, K. R.; Coleman, P. J.; Alvarez, J. C.; Dreher, S. D.; Garbaccio, R. M.; Terrett, N. K.; Tillyer, R. D.; Truppo, M. D.; Parmee, E. $\mathrm{R}$. The importance of synthetic chemistry in the pharmaceutical industry. Science 2019, 363, eaat0805.

(4) (a) Mäder, P.; Kattner, L. Sulfoximines as Rising Stars in Modern Drug Discovery? Current Status and Perspective on an Emerging Functional Group in Medicinal Chemistry. J. Med. Chem. 2020, 63, 1424314275. (b) Lücking, U. Neglected sulfur(VI) pharmacophores in drug discovery: exploration of novel chemical space by the interplay of drug design and method development Org. Chem. Front. 2019, 6, 13191324.

(5) Bull, J. A.; Croft, R. A.; Davis, O. A.; Doran, R.; Morgan, K. F. Oxetanes: recent advances in synthesis, reactivity, and medicinal chemistry. Chem. Rev. 2016, 116, 12150-12233.

(6) (a) Wuitschik, G.; Rogers-Evans, M.; Müller, K.; Fischer, H.; Wagner, B.; Schuler, F.; Polonchuk, L.; Carreira, E. M. Oxetanes as promising modules in drug discovery. Angew. Chem. Int. Ed. 2006, 45, 7736-7739. (b) Wuitschik, G.; Rogers-Evans, M.; Buckl, A.; Bernasconi, M.; Märki, M.; Godel, T.; Fischer, H.; Wagner, B.; Parrilla, I.; Schuler, F.; Schneider, J.; Alker, A.; Schweizer, W. B.; Müller, K.; Carreira, E. M. Spirocyclic oxetanes: synthesis and properties. Angew. Chem. Int. Ed. 2008, 47, 4512-4515. (c) Burkhard, J. A.; Wagner, B.; Fischer, H.; Schuler, F.; Müller, K.; Carreira, E. M. Synthesis of azaspirocycles and their evaluation in drug discovery. Angew. Chem. Int. Ed. 2010, 49, 3524-3527. d) Wuitschik, G.; Carreira, E. M.; Wagner, B.; Fischer, H.; Parrilla, I.; Schuler, F.; Rogers-Evans, M.; Müller, K. Oxetanes in Drug Discovery: Structural and Synthetic Insights. J. Med. Chem. 2010, 53, 3227-3246.

(7) Lovering, F.; Bikker, J.; Humblet, C. Escape from flatland: increasing saturation as an approach to improving clinical success. J. Med. Chem. 2009, 52, 6752-6756. 
(8) Berthelot, M.; Besseau, F.; Laurence, C. The Hydrogen-Bond Basicity $\mathrm{pK}_{\mathrm{HB}}$ Scale of Peroxides and Ethers. Eur. J. Org. Chem. 1998, 1998, 925-931.

(9) (a) Powell, N. H.; Clarkson, G. J.; Notman, R.; Raubo, P.; Martin, N. G.; Shipman, M. Synthesis and structure of oxetane containing tripeptide motifs. Chem. Commun. 2014, 50, 8797-8800. (b) Möller, G. P.; Müller, S.; Wolfstädter, B. T.; Wolfrum, S.; Schepmann, D.; Wünsch, B.; Carreira, E. M. Oxetanyl amino acids for peptidomimetics. Org. Lett. 2017, 19, 2510-2513.

(10) Lassalas, P.; Oukoloff, K.; Makani, V.; James, M.; Tran, V.; Yao, Y.; Huang, L.; Vijayendran, K.; Monti, L.; Trojanowski, J. Q.; Lee, V. M.-Y.; Kozlowski, M. C.; Smith, A. B.; Brunden, K. R.; Ballatore, C. Evaluation of oxetan-3-ol, thietan-3-ol, and derivatives thereof as bioisosteres of the carboxylic acid functional group. ACS Med. Chem. Lett. 2017, 8, 864-868.

(11) For synthetic studies on thioester isosteres, see: Croft, R. A.; Mousseau, J. J.; Choi, C.; Bull, J. A. Lithium-catalyzed thiol alkylation with tertiary and secondary alcohols: synthesis of 3-sulfanyl-oxetanes as bioisosteres. Chem. Eur. J. 2018, 24, 818-821.

(12) (a) Stepan, A. F.; Karki, K.; McDonald, W. S.; Dorff, P. H.; Dutra, J. K.; DiRico, K. J.; Won, A.; Subramanyam, C.; Efremov, I. V.; O'Donnell, C. J.; Nolan, C. E.; Becker, S. L.; Pustilnik, L. R.; Sneed, B.; Sun, H.; Lu, Y.; Robshaw, A. E.; Riddell, D.; O'Sullivan, T. J.; Sibley, E.; Capetta, S.; Atchison, K.; Hallgren, A. J.; Miller, E.; Wood, A.; Obach, R. S. Metabolism-directed design of oxetane-containing arylsulfonamide derivatives as $\gamma$-secretase inhibitors. J. Med. Chem. 2011, 54, 7772-7783. (b) Dowling, J. E.; Alimzhanov, M.; Bao, L.; Block, M. H.; Chuaqui, C.; Cooke, E. L.; Denz, C. R.; Hird, A.; Huang, S.; Larsen, N. A.; Peng, B.; Pontz, T. W.; Rivard-Costa, C.; Saeh, J. C.; Thakur, K.; Ye, Q.; Zhang, T.; Lyne, P. D. Structure and property based design of pyrazolo[1,5-a]pyrimidine inhibitors of CK2 kinase with activity in vivo. ACS Med. Chem. Lett. 2013, 4, 800-805. (c) Kung, P. P.; Bingham, P.; Brooun, A.; Collins, M.; Deng, Y. L.; Dinh, D.; Fan, C.; Gajiwala, K. S.; Grantner, R.; Gukasyan, H. J.; Hu, W.; Huang, B.; Kania, R.; Kephart, S. E.; Krivacic, C.; Kumpf, R. A.; Khamphavong, P.; Kraus, M.; Liu, W.; Maegley, K. A.; Nguyen, L.; Ren, S.; Richter, D.; Rollins, R. A.; Sach, N.; Sharma, S.; Sherrill, J.; Spangler, J.; Stewart, A. E.; Sutton, S.; Uryu, S.; Verhelle, D.; Wang, H.; Wang, S.; Wythes, M.; Xin, S.; Yamazaki, S.; Zhu, H.; Zhu, J.; Zehnder, L.; Edwards, M. Optimization of orally bioavailable enhancer of Zeste Homolog 2 (EZH2) inhibitors using ligand and property-based design strategies: identification of development candidate $(R)-5,8$-dichloro-7(methoxy(oxetan-3-yl)methyl)-2-((4-methoxy-6-methyl-2-oxo-1,2-dihydropyridin-3-yl)methyl)-3,4-dihydroisoquinolin-1(2H)-one (PF06821497). J. Med. Chem. 2018, 61, 650-665.

(13) Other work suggests 3 -substituted oxetanes are not substrates for Phase 2 clearance pathways: (a) Toselli, F.; Fredenwall, M.; Svensson, P.; Li, X.-Q.; Johansson, A.; Weidolf, L.; Hayes, M. A. Hip to be square: oxetanes as design elements to alter metabolic pathways. $J$. Med. Chem. 2019, 62, 7383-7399. (b) Duncton, M. A. J.; Estiarte, M. A.; Tan, D.; Kaub, C.; O’Mahony, D. J. R.; Johnson, R. J.; Cox, M.; Edwards, W. T.; Wan, M.; Kincaid, J.; Kelly, M. G. Preparation of aryloxetanes and arylazetidines by use of an alkyl-aryl Suzuki-coupling. Org. Lett. 2008, 10, 3259-3262. (c) Stepan, A. F.; Kauffman, G. W.; Keefer, C. E.; Verhoest, P. R.; Edwards, M. Evaluating the differences in cycloalkyl ether metabolism using the design parameter "Lipophilic Metabolism Efficiency" (LipMetE) and a matched molecular pairs analysis. J. Med. Chem. 2013, 56, 6985-6990.

(14) (a) Preston, G. W.; Wilson, A. Photo-induced covalent cross-linking for the analysis of biomolecular interactions. J. Chem. Soc. Rev. 2013, 42, 3289-3301. (b) Galardy, R. E.; Craig, L. C.; Jamieson, J. D.; Printz, M. P. Photoaffinity labeling of peptide hormone binding sites. J. Biol. Chem. 1974, 249, 3510-3518.
(15) (a) Boscá, F.; Miranda, M. A. Photosensitizing drugs containing the benzophenone chromophore. J. Photochem. Photobiol. B Biol. 1998, 43, 1-26. (b) Cuquerella, M. C.; Lhiaubet-Vallet, V.; Cadet, J.; Miranda, M. A. Benzophenone photosensitized DNA damage. Acc. Chem. Res. 2012, 45, 1558-1570.

(16) Hodous, B. L.; Kim, J. L.; Wilson, K. J.; Wilson, D.; Zhang, Y. Compositions useful for treating disorders related to KIT. US20150111887 A1, 2015.

(17) (a) Kubo, Y.; Suto, M.; Araki, T.; Mazzocchi, P. H.; Klingler, L.; Shook, D.; Somich, C. Photochemical reactions of N-methylnaphthalene-2, 3-dicarboximide with alkenes. J. Org. Chem. 1986, 51, 44044411. (b) Xue, J.; Zhang, Y.; Wu, T.; Fun, H. K.; Xu, J. H. Photoinduced [2+2] cycloadditions (the Paterno-Büchi reaction) of $1 \mathrm{H}-1$ acetylindole-2, 3-dione with alkenes. J. Chem. Soc. Perkin Trans. 1. 2001, 183-191. (c) Matsumura, K.; Mori, T.; Inoue, Y. Solvent and temperature effects on diastereodifferentiating Paternó-Büchi reaction of chiral alkyl cyanobenzoates with diphenylethene upon direct versus charge-transfer excitation. J. Org. Chem. 2010, 75, 5461-5469. (d) Rykaczewski, K. A.; Schindler, C. S. Visible light-enabled PaternòBüchi reaction via triplet energy transfer for the synthesis of oxetanes. Org. Lett. 2020, 22, 6516-6519.

(18) Croft, R. A.; Mousseau, J. J.; Choi, C.; Bull, J. A. Structurally divergent lithium catalyzed Friedel-Crafts reactions on oxetan-3-ols: synthesis of 3,3-diaryloxetanes and 2,3-dihydrobenzofurans. Chem. Eur. J. 2016, 22, 16271-16276.

(19) (a) Croft, R. A.; Mousseau, J. J.; Choi, C.; Bull, J. A. Oxetane ethers are formed reversibly in the lithium-catalyzed Friedel-Crafts alkylation of phenols with oxetanols: synthesis of dihydrobenzofurans, diaryloxetanes, and oxetane ethers. Tetrahedron 2018, 74, 5427-5435. (b) Croft, R. A.; Dubois, M. A. J.; Boddy, A. J.; Denis, C.; Lazaridou, A.; Voisin-Chiret, A. S.; Bureau, R.; Choi, C.; Mousseau, J. J.; Bull, J. A. Catalytic Friedel-Crafts reaction on saturated heterocycles and small rings for $\mathrm{sp}^{3}-\mathrm{sp}^{2}$ coupling of medicinally relevant fragments. Eur. J. Org. Chem. 2019, 2019, 5385-5395. c) Dubois, M. A. J.; Smith, M. A.; White, A. J. P.; Lee Wei Jie, A.; Mousseau, J. J.; Choi, C.; Bull, J. A. Short synthesis of oxetane and azetidine 3-aryl-3-carboxylic acid derivatives by selective furan oxidative cleavage. Org. Lett. 2020, 22, 5279-5283. d) For azetidines, also see: Denis, C.; Dubois, M. A. J.; Voisin-Chiret, A. S.; Bureau, R.; Choi, C.; Mousseau, J. J.; Bull, J. A. Synthesis of 3,3-Diarylazetidines by Calcium(II)-Catalyzed FriedelCrafts Reaction of Azetidinols with Unexpected Cbz Enhanced Reactivity. Org. Lett. 2019, 21, 300-304.

(20) (a) Lipinski, C. A.; Lombardo, F.; Dominy, B. W.; Feeney, P. J. Experimental and computational approaches to estimate solubility and permeability in drug discovery and development settings. Adv. Drug Deliv. Rev. 1997, 23, 3-25. (b) Murray, C. W.; Rees, D. C. Opportunity knocks: organic chemistry for fragment-based drug discovery (FBDD). Angew. Chem. Int. Ed. 2016, 55, 488-492. (c) Nadin, A.; Hattotuwagama, C.; Churcher, I. Lead-oriented synthesis: a new opportunity for synthetic chemistry. Angew. Chem. Int. Ed. 2012, 51, 1114-1122.

(21) This outcome was consistent with a study by Zhang and Rao on silica gel mediated Friedel-Crafts alkylation of 3-indolylmethanols: Zou, Y.; Chen, C.; Chen, X.; Zhang, X.; Rao, W. Silica gel mediated Friedel-Crafts alkylation of 3-indolylmethanols with indoles: synthesis of unsymmetrical bis(3-indolyl)methanes. Eur. J. Org. Chem. 2017, 2266-2271.

(22) For development of $\mathrm{CaNTf}_{2} / \mathrm{BuNPF}_{6}$ catalysts, see: Niggemann, M.; Meel, M. J. Calcium-Catalyzed Friedel-Crafts Alkylation at Room Temperature. Angew. Chem. Int. Ed. 2010, 49, 3684-3687. 
3,3-Diaryloxetanes as potential bioisosteres

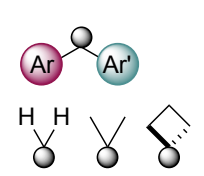

Matched molecular pair analysis of

"drug-like" compounds

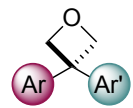

- generally $\mathrm{pH}$ stable

$$
\text { - elogD } ~ 3.3
$$

- $7.0 \mu \mathrm{L} / \mathrm{min} / \mathrm{mg}<\mathrm{HLM}<80 \mu \mathrm{L} / \mathrm{min} / \mathrm{mg}$

- RRCK: 4.80-24.4 $10^{-6} \mathrm{~cm} / \mathrm{s}$

kinetic solubility: 0.1-600 $\mu \mathrm{M}$ 